\title{
THE USE OF THE P WAVE FOR CONTROL OF A PACEMAKER IN HEART BLOCK
}

\author{
BY \\ C. K. BATTYE AND F. E. WEALE \\ From the Physics Department, Guy's Hospital Medical School, and the Thoracic Surgical Unit, \\ Guy's Hospital, London
}

(RECEIVED FOR PUBLICATION DECEMBER 29, 1959)

Since the introduction of the electronic artificial pacemaker for clinical use in cases of postoperative heart block, the idea has naturally occurred to many workers that the electrical stimulus causing the ventricles to contract should be applied at the correct point in the cardiac cycle so as to produce a response similar to that which would occur during normal functioning of the heart. This can be achieved by picking up the $P$ wave from suitable leads and using this to trigger a delay network which produces the stimulating pulse after a time corresponding to the normal P-Q interval. Methods used so far (Folkman and Watkins, 1958; Vanderschmidt, 1958; Stephenson, Edwards, Jolly, and Scott, 1959) have picked up the $P$ wave from a lead sutured to the surface of the atrium and have applied the stimulus to a similar lead on the surface of the ventricular myocardium.

The purpose of this communication is to describe a system in which the $P$ wave is picked up and the stimulating impulse applied via a twin catheter electrode inserted into the heart through the right external jugular vein, and to report its trial in experiments with dogs.

Previously published work shows that signals corresponding to the atrial contraction are readily picked up from an electrode situated in the upper part of the right atrium, and that the signal resulting from the contraction of the ventricles is small in this position (e.g., Kisch, Groedel, and Borchardt, 1947). It has further been shown that it is difficult to stimulate the ventricle through a lead situated in the atrium without using relatively large electrical impulses of about 20v (Davies, Leatham, and Robinson, 1959) compared with the threshold of stimulation for an electrode situated in the right ventricle (Nightingale and Weale, 1960; Furman and Robinson, 1959) which is only about $0.2 \mathrm{v}$. The feasibility of allowing an electrode to remain in the right ventricle for prolonged periods was discussed in a preliminary paper (Weale, 1959). Sacrifice of a dog with an clectrode indwelling for 11 weeks revealed the presence of tricuspid and subtricuspid vegetations. and, microscopically, fibroblastic proliferation of the cusps. The liver, both macro- and microscopically, appeared normal. From these investigations it would appear that tricuspid damage may occur after a period of about four weeks. Anticoagulant therapy, however, may prolong this period. Furman and Robinson (1959) report the use of intracardiac catheters in humans for as long as 10 weeks.

\section{Preliminary InVestigations}

The surface of the heart had first been monitored by Sir Thomas Lewis as early as 1914 . A prerequisite for triggering the ventricular impulse from the atria was the demonstration of a $P$ wave of sufficient amplitude and constancy, but we found the $P$ waves from the atrial surface inadequate for the purpose of triggering. In particular there were marked variations from place to place, and significant differences in the amplitude of $\mathbf{P}$ waves as between open and closed chests. Familiarity with the intraventricular electrode led to the assay of intracardiac electrocardiograms.

A study of the right intra-atrial E.C.G. revealed (a) broad agreement with the findings of previous workers (e.g., Hecht, 1946 ; Battro and Bidoggia, 1947 ; Levine, Hellems, Wittenborg, and Dexter, 1949 ; Kossmann, Berger, Rader, Brumlík, Briller, and Donnelly, 1950), and (b) that only the intraatrial $P$ wave possessed the amplitude and constancy of outline needed for triggering the ventricular system.

Hecht (1946) states that, in the study of intraatrial electrocardiograms, "conclusions drawn from animal experiments can safely be applied to human electrocardiography." 

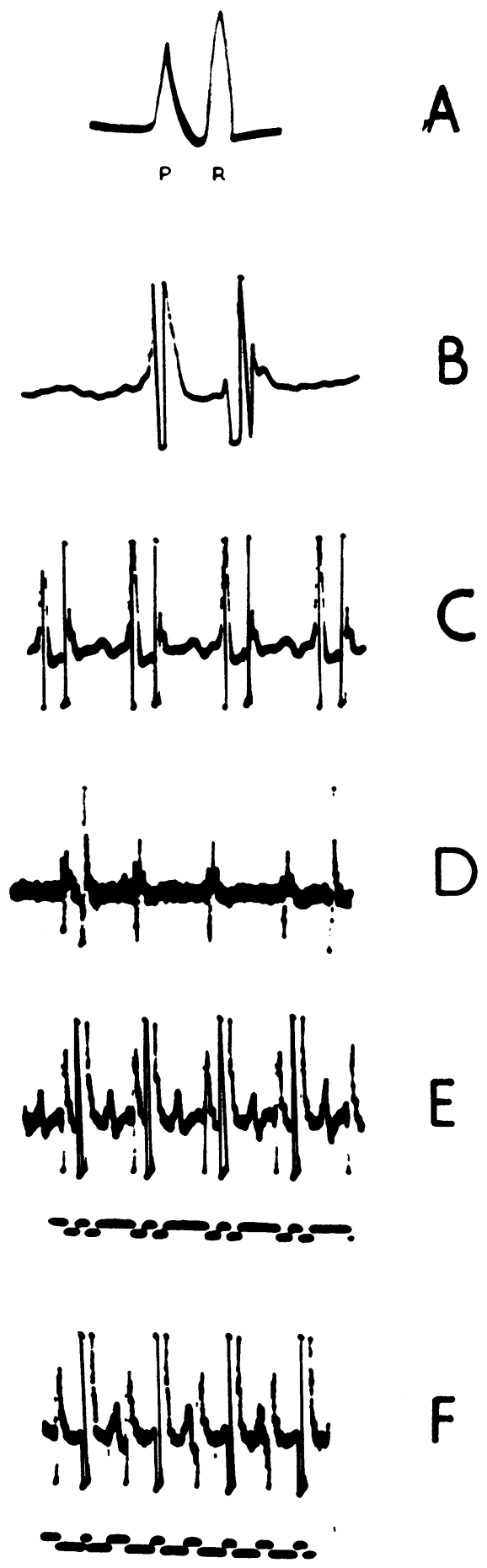

Using a silver electrode mounted at the end of $\stackrel{+}{\circ}$ an insulated conducting catheter, it was found that the $\mathbf{P}$ wave recorded in the upper right atrium was $\frac{\overline{\bar{P}}}{}$ typically a negative-going, fast-rising, monophasic $\widehat{\varnothing}$ pulse (Fig. 1 A). Though considerable variation in the wave shape could be obtained by varying ${ }^{\text {s }}$ the position of the electrode, a rapid transition? of a few millivolts was always observed. It was $\vec{A}$ confirmed that the potentials recorded in the upper atrium due to ventricular contraction were similar $\vec{x}$ in size to those due to the atrial contraction.

The size of the stimulus artefact produced at $\vec{r}$ the pick-up electrode by a $1 \mathrm{msec}$. pulse of about ${ }_{-}^{N}$ $1.5 \mathrm{v}$ applied to a similar electrode $5 \mathrm{~cm}$. away in $\vec{V}$ a tank of normal saline was determined and foundo to be $125 \mathrm{mv}$. in amplitude and about $60 \mathrm{msec}$. in duration. It was considered that this would $\bar{c}$ approximate to the stimulus artefact inside the ventricle. It was therefore necessary to design an amplifier which would recover rapidly from this signal, which represents a considerable overload,. being about 60 times the signal it was required to detect.

\section{Apparatus and Method}

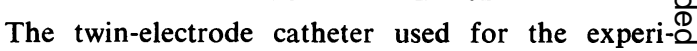
ments is shown in Fig. 2. (Electrode A lay in the $\overrightarrow{\vec{F}}$ right atrium whilst $B$ passed through into the right? ventricle.) The common electrode, which wasearthed, was a silver plate $20 \mathrm{~cm} .{ }^{2}$ in area strapped tof the outside of the chest.

The signal from electrode $A$ was fed to an electronic circuit, designed to respond only to the $P$ wave and not to the wave arising from its own stimulation of the ventricle. This circuit, after differentiating and limiting the signal, uses it to produce a stimulus after. a fixed delay which can be adjusted. (Details of theo circuit used will be published elsewhere, but meanwhile circuit diagrams are available from theo authors.)

The procedure for anaesthetizing the $\operatorname{dog} \frac{D}{O}$ producing heart block, and cannulating the righte. external jugular vein was the same as described elsewhere (Nightingale and Weale, 1960): Briefly, heart block was established after righĩ thoracotomy, temporary occlusion of both venae cavae, and entry of the right atrium. The bundle of:

FIG. 1.-A, a typical atrial electrogram recorded from the uppe? right atrium (polarity negative upwards); B, an atrial electrogram after differentiation, amplification and limiting (polarity positive upwards); C, as B but time scale reduced showin? successive heart beats; $D$, differentiated atrial wave form afte production of heart block showing four atrial contractions an $\$$ two ventricular contractions; E, differentiated atrial electrograrm during synchronized pacemaking (upper trace), showing $P$ wave followed by superimposed stimulus artefact and QRS complex, the lowar trace shows the output from the delay pulse generator $F$, as $E$, but with longer $P-Q$ interval. 

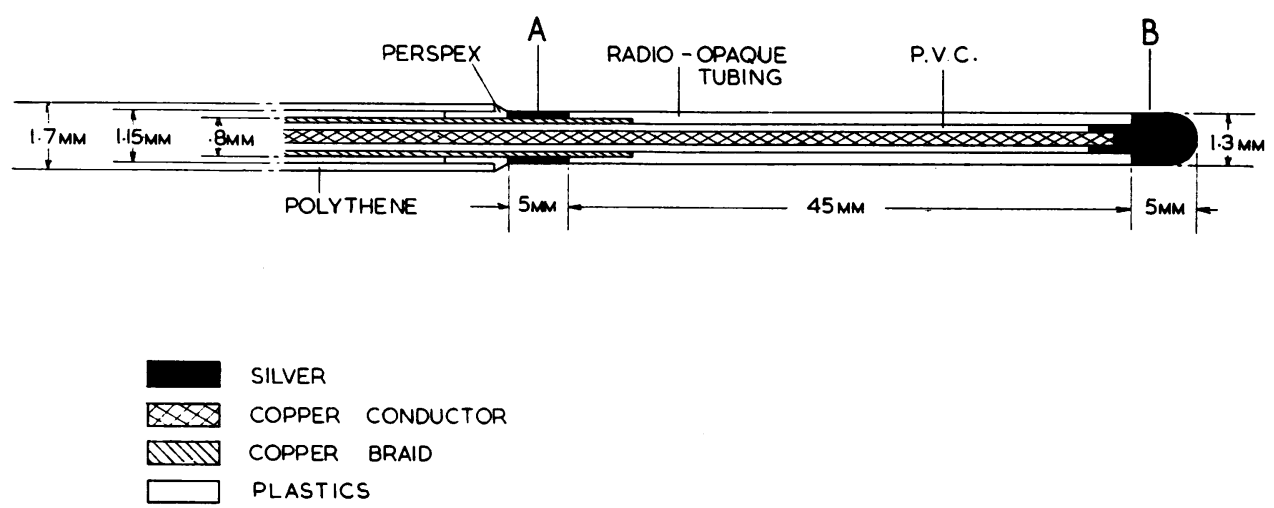

FIG. 2.-Twin electrode intracardiac catheter.

His was divided by means of a Bard Parker No. 15 blade inserted under the attachment of the septal cusp of the tricuspid valve. In the earlier experiments the position of the catheter was checked by fluoroscopy using an image intensifier, but later it was found more convenient to check it by recording the electrogram from the tip (B) as the catheter was introduced. The point of entry into the atrium was marked by the appearance of large electrical signals, whilst the point at which the tip passed through the tricuspid valve was marked by the sudden appearance of potentials of large amplitude and duration corresponding to the ventricular contractions. The amplifier was then connected to $A$ in order to check the pick-up of the atrial electrogram. Fig. 1B and $1 \mathrm{C}$ shows the potential as it appeared after its passage through the differentiator, amplifier, and limiter.

After production of heart block, a radiograph showing the position of the electrodes was taken (Fig. 3), and the signal from the atrial electrode was

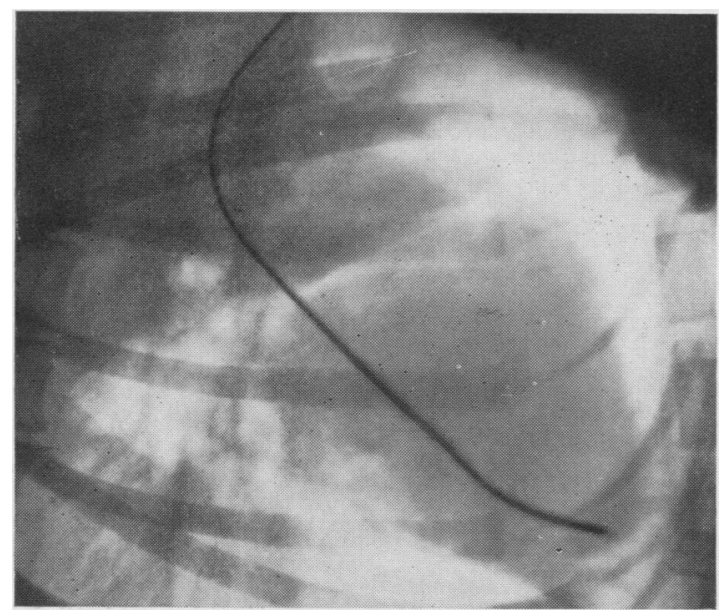

FIG. 3.-Right lateral radiograph showing position of catheter and electrodes. recorded (Fig. 1D). The stimulator was then switched on and its rate was adjusted to be somewhat less than the physiological rate. On connecting the synchronizing signal to the stimulator it became synchronized to the atrial pulse (Fig. 1E and 1F).

\section{Discussion}

Several advantages have been suggested for pacemaking by this method over the commonly used free-running pacemaker. First, the use of electrodes which lie directly in the blood stream is not attended by the commonly observed fibrosis (Watkins, 1959) of the surrounding tissues with consequent increase in stimulus threshold over a long period. Secondly, the heart rate is under physiological control and will adjust itself during exercise (Stephenson et al., 1959). In applying this method to post-operative clinical cases this may not be an important factor, but even here sudden changes in cardiac output may be required under conditions of emotional or physiological stress. Furthermore, though the supplementation of a natural physiological function may be unimportant in a relatively normal heart, it may become increasingly important when the heart is diseased. No animal experiment can evaluate this aspect.

It is likely that the cardiac output will be enhanced by the correct phasing of atrial and ventricular contractions. Work by Siecke and Essex (1958) suggests that a maximum in cardiac output in dogs would occur at a delay of about $150 \mathrm{msec}$. between the appearance of the $P$ wave and the triggering pulse; further experiments to study cardiac output under these conditions are in progress, and it is hoped to report the results shortly.

The use of a synchronized system ensures that during recovery from heart block a smooth 
transition will occur without the production of extrasystoles as with unsynchronized systems.

It has also been suggested that the stimulation of the ventricles in certain phases might produce ventricular fibrillation (Wiggers and Wégria, 1940). Maaske and Bromberger-Barnea (1958) investigated this possibility and showed that for the undamaged heart no such effect could be produced. They state, however, that myocardial injury conditions the heart to fibrillation, and a "vulnerable period" may then exist. The use of a synchronized system avoids this difficulty.

A major disadvantage of a pacemaker in which the stimulating pulse is initiated only on receipt of a $P$ wave is that the system will fail if the $P$ wave is not picked up for any reason. This has been avoided in the system used here by adjusting the stimulator so that in the absence of synchronizing signals it runs at a rate about $30 \%$ lower than the physiological rate. On the application of synchronizing signals the stimulator is "pulled" into synchronism and the rate increases.

It is not, as yet, certain whether electrocardiographic or fluoroscopic control is the better for checking the position of the electrode. Much may depend upon local circumstances, though, on the whole, electrocardiographic control would appear to be more readily available.

It is a pleasure to thank Sir Russell Brock for his encouragement of this work and for providing experimental facilities; and Mr. F. Huthwaite for manufacturing the catheters and electrodes used.

\section{REFERENCE3}

Battro, A., and Bidoggia, H. (1947). Amer. Heart J., 33, 604. Davies, J. G., Leatham, A., and Robinson, B. F. (1959). 'Lancet, 1 , 583.

Folkman, M. J., and Watkins, E. (1958). Surg. Forum, 1957, 8, 331. Furman, S., and Robinson, G. (1959). Ibid., 1958, 9, 245.

Hecht, H. H. (1946). Amer. Heart J., 32, 39.

Kisch, B., Groedel, F. M., and Borchardt, P. R. (1947). Exp. Med. Surg., 5, 426.

Kossmann, C. E., Berger, A. R., Rader, B., Brumlík, J., Briller, S. A., and Donnelly, J. H. (1950). Circulation, 2, 10 .

Levine, H. D., Hellems, H. K., Wittenborg, M. H., and Dexter, L. (1949). Amer. Heart J., 37, 46.

Maaske, C. A., and Bromberger-Barnea, B. (1958). Amer. J. Physiol., 195, 575.

Nightingale, A., and Weale, F. E. (1960). Guy's Hosp. Rep. In the

press.
Siecke, H., and Essex, H. E. (1958). Amer. J. Physiol., 195, 429.

Siecke, H., and Essex, H. E. (1958). Amer. J. Physiol., 195, 429.
Stephenson, S. E., Edwards, W. H., Jolly, P. C., and Scott, H. W. (1959). J. thorac. Cardiovasc. Surg., 38, 604.

Vanderschmidt, G. H. (1958). Electronics, Engng ed., 31, Nov. 21, p. 80 .

Watkins, E. (1959). I.R.E. Transactions on Medical Electronics, $M E$ 6, 36 .

Weale, F. E. (1959), Lancet, $2,73$.

Wiggers, C. J., and Wégria, R. (1940). Amer. J. Physiol., 128, 500. 